\title{
ВАРИАЦИИ ПРЕЦЕДЕНТНЫХ ФЕНОМЕНОВ В МЕДИАДИСКУРСЕ, ИЛИ ЕЩЕ ОДНА ПОПЫТКА «ПОВЕРИТЬ АЛГЕБРОЙ ГАРМОНИЮ»
}

\author{
В. Г. Шимко, О. О. Борискина
}

Воронежский государственный университет

\section{THE VARIATION OF CATCHPHRASES IN DIGITAL MEDIA}

\author{
V. G. Shimko, O. O. Boriskina \\ Voronezh State University
}

\begin{abstract}
Аннотация: быстрые темпы развития циифровой реальности требуют пересмотра и уточнений общепринятых положений теории интертекстуальности, включая возможность и способность прецедентных феноменов к трансформации и модификации, предель и закономерности формального или содержательного, осознанного или неосознанного варьирования. В статье на корпусных данных рассматриваются границы и параметры прецедентности: относительная устойчивость прецедентных феноменов, с одной сторонь, и их изменчивость, способность к трансформации - с другой. Средством реализации трансформационного потенциала прецедентного феномена является квазицитирование. Соотночение прямого ицитирования и квазицитирования зависит от длины прецедентного феномена и сочетаемостных особенностей его элементов. Прецедентные феномены, «доживиие» до этапа модификации, демонстрируют разную степень изменчивости и вариативности. Квазицитированию скорее подвержены фразы, прецедентность которых достаточно устойчива. Анализ возможностей и форм проявления квазицитирования позволил выявить основнье принципь модификации ПФ: добавление к прецедентному тексту нового элемента, на $90 \%$ атрибутивов; контекстно обусловленная замена одного или нескольких элементов ПФ, в основном онимов (антропонимов и топонимов) другими онимами или просто членами одной парадигмы; зафиксированы антонимические и синонимические замены. Вариативность ПФ также проявляется в «перемене мест слагаемых», в смешивании с другими прецедентными феноменами, а также в сокращении количества элементов ПФ. «Высшим пилотажем» интертекстуальности с максимально высокой степенью устойчивости, по всей видимости, следует считать употребление всего прецедентного высказывания в атрибутивной позиции при существительном.

Ключевые слова: интертекстуальность, прецедентный феномен, изменчивость, вариативность, трансформация, модификация.
\end{abstract}

\begin{abstract}
: the rapid pace of digital reality development requires a reconsideration and clarification of generally accepted provisions of the theory of intertextuality. These provisions include the possibility of precedent phenomena transformation and modification and the limits and patterns of forms and meanings. The article employs corpus data to examine the boundaries and parameters of culturally significant phenomena: their relative stability, on the one hand, and their variability, ability to transform, on the other. A means of realizing the transformational potential of a culturally significant phenomenon is quasi-citation. The ratio of direct citation to quasi-citation depends on the length of the culturally significant phenomenon and the compatibility features of its elements. Culturally significant phenomena that have "survived" to the stage of modification demonstrate a different degree of variability. Phrases with a higher degree of cultural significance are more likely to be quasi-cited. The analysis of possible forms of quasi-citation made it possible to identify the basic principles of modifications of these phrases, which include adding a new element, a contextually determined replacement of one or several elements of the precedent phrase, mainly onyms (anthroponyms and toponyms) with other onyms or simply members of the same paradigm. Variability of culturally significant phrases is also manifested in mixing with other culturally significant phenomena, as well as in the reduction of the number of precedent phrase elements. Apparently, the use of the entire precedent statement in an attributive position with a noun should be considered as "top performance" of intertextuality with the highest possible degree of stability.
\end{abstract}

Key words: intertextuality, catchphrase, language change, variation, transformation, modification.

(C) Шимко В. Г., Борискина О. О., 2020

Контент доступен под лицензией Creative Commons Attribution 4.0 License.

The content is available under Creative Commons Attribution 4.0 License. 
Мы живем в эпоху тотальной цифровизации, когда некогда непопулярные старания Сальери «поверить алгеброй гармонию» уже воспринимаются как норма или, скорее, требование времени. Работа лингвиста с материалом языковых корпусов относится к сфере цифровых технологий, а полученные данные и выводы корпусного исследования обеспечивают развитие и приращение знания в цифровых гуманитарных науках - новой междисциплинарной области знания [1]. Быстрые темпы развития цифровой реальности поднимают новые вопросы или требуют пересмотра и уточнений общепринятых положений теории интертекстуальности, включая границы и параметры прецедентности: относительная устойчивость прецедентных феноменов, с одной стороны, и их изменчивость, способность к трансформации - с другой.

Коммуникативное обращение прецеедентных феноменов (далее ПФ) в медиадискурсе зависит от ряда причин, среди которых выделяют стремление к экспрессивности, манипулированию через привлечение внимания аудитории, а также языковую игру. Безусловно, ПФ - крайне выгодное с точки зрения языковой экономии средство достижения подобных авторских интенций при передаче значимой информации, поскольку прецедентный феномен может заменить многословные объяснения или «нормальные тексты» [2, с. 48]. При этом ПФ, как любой вторичный языковой знак, «произволен, конвенционален, формально и содержательно вариативен» [3, с. 355], проходит этапы становления, трансформации [4] и смерти (когда он перестает служить надежным средством передачи значимой информации от поколения к поколению). Снижение прецедентности ПФ нередко приводит к его «забвению», но при наличии в лингвокультуре благоприятных условий и, главное, твердого намерения и заинтересованности одного или нескольких членов языкового коллектива ПФ может возродиться, как это случилось, например, с ПФ «Арминий» с целью объединения германских племен в середине XIX в. [5]. Многообразие форм бытования и изменчивости ПФ ярко свидетельствует об их «жизненности», а также обусловливает актуальность исследования их функциональной нагруженности в тексте и способности к трансформации и модификации [4-8]. Остается открытым вопрос, до какой степени может изменяться ПФ, не теряя своей целостности и функциональной нагруженности? Есть ли пределы вариативности ПФ?

Считается, в частности, что содержание прецедентного текста, остается, как правило, константным, а форма варьируется [3, с. 360], однако цифровой медиадискурс, как показал анализ, стремительно превращается в среду, способствующую не только формальному, но и содержательному варьированию ПФ.
Данное исследование посвящено изучению одного из значимых аспектов интертекстуальности - пределам и закономерностям формального и содержательного варьирования прецедентных феноменов.

Следуя базовым принципам подхода к прецедентному феномену как к универсальному средству передачи всех культурных фактов народа (см. работы Ю. Н. Караулова, В. Г. Костомарова, А. П. Чудинова, Г. Г. Слышкина, Л. И. Гришаевой и др. [6-10]), мы приветствуем широкое понимание интертекстуальности как присутствие в тексте элементов «чужого», написанного ранее, текста. При этом для решения задач настоящего исследования целесообразно нивелировать различия между разными способами кодирования прецедентного феномена (прецедентная ситуация, прецедентное высказывание, прецедентное имя, прецедентный текст). В качестве объекта исследования рассматривались прецедентные феномены в широком смысле, бытующие в англоязычном медийном дискурсе. Цифровое пространство бытования ПФ представлено корпусом News on the Web (NOW [11]), в котором собраны тексты медиадискурса с 2010 г. по настоящий момент для 20 региональных вариантов английского языка. Предметом исследования послужили трансформации и модификации двадцати ПФ более в чем восьми тысячах корпусных контекстах употребления ПФ.

Как правило, жизнь ПФ начинается с его появления в дискурсе в виде прямой ц̧итащзи (дословное цитирование с или без ссылки на источник). Его закрепление в лингвокультуре происходит посредством увеличения коммуникативного обращения прямой цитации в разных типах дискурса. Следующий этап - модификации прецедентного феномена - связан с квазицитированием - воспроизведением фразы или части фразы в умышленно измененном виде в результате его вовлечения в языковую игру. Представляют особый интерес случаи «мутации» прецедентного феномена, при которых внешняя форма остается неизменной, однако функциональная или смысловая составляющая постоянно обновляется. Так, например, ПФ «Drain the swamp» ${ }^{1}$, отсылающий к ситуации осушения заболоченной местности вокруг столицы США Вашингтона в начале XIX в., в смысле покорения природы используется в англоязычном политическом дискурсе как ПФ в контексте первого этапа покорения североамериканских индейских племен с середины XIX в. В XX в. Президент США предложил «осушить бюрократическое болото»; в контексте войны с терроризмом звучал призыв «осушить террористическое болото». В 2016 г. Д. Трамп вновь обратился к ПФ «Drain the swamp» в ходе своей

${ }^{1}$ Дословно осушить болота, в русскоязычной культуре бытует фразеологизм «свернуть горы» с похожим значением. 
предвыборной кампании в контексте решения проблем в высших федеральных органах власти.

Как показал анализ, на этапе модификации прецедентный феномен продолжает бытовать в языковой культуре как в неизменном (в виде прямых цитаций), так и в измененном (в виде квазицитаций) виде. Однако далеко не все ПФ доходят до этапа модификации. Как правило, если сокращается коммуникативное обращение ПФ в дискурсе - которое со временем может вовсе прекратиться - то фраза перестает выполнять функцию ПФ. Но пока фраза используется в функции ПФ в медиадискурсе, за этим можно наблюдать. Лучше это делать на специальных цифровых площадках - языковых корпусах [12].

Современные языковые корпуса дают возможность проследить трансформации и модификации ПФ в цифровом медиапространстве, оценив соотношение его прямых цитаций и квазицитаций. Выявление подобных корреляций может оказаться значимым не столько в общетеоретическом отношении, сколько в прикладном, в особенности для цифровой гуманитаристики и корпусной лингвистики, например, чтобы использовать принципы и способы преобразования ПФ для машинного обучения. Качественный и количественный анализ цитаций и квазицитаций поможет пролить свет на вопросы: Как можно определить, какие ПФ более подвержены изменениям? Можно ли выявить закономерности варьирования ПФ? Есть ли пределы изменчивости ПФ?

\section{Принципы отбора материала}

В качестве источника прецедентных феноменов мы использовали Википедию. Изначально на странице Political catchphrases (https://en.wikipedia. org/ wiki/Category:Political_catchphrases) было отобрано около 250 фраз из американского, британского, канадского, австралийского и ирландского медийного политического дискурса. Для медийного телевизионного дискурса источником высказываний стала страница Википедии List of catchphrases (https://en.wikipedia. org/wiki/List_of_catchphrases). На этапе отбора материала из телевизионного дискурса мы сознательно ограничились только фразами из американских и британских источников, поскольку ПФ из канадских или австралийских сериалов и телешоу малоинформативны с точки зрения их общеизвестности и значимости для всего англоязычного мира.

При дальнейшем отборе материала учитывались уточненные в ходе настоящего исследования критерии Ю. Н. Караулова [13]:

- сверхличностный характер ПФ, т. е. его общеизвестность как для современников, так и для предшественников;
- значимость ПФ в познавательном или эмоциональном отношении;

- частотность коммуникативного обращения фразы в качестве ПФ.

При работе с корпусными данными уточненные критерии применялись следующим образом. Сверхличностный характер фразы проявлялся в наличии контекстов ПФ-употребления в разных новостных изданиях и в разных вариантах английского языка.

Значимость ПФ в познавательном или эмоциональном отношении и его коммуникативное обращение прослеживались на большом количестве употреблений фразы в качестве ПФ в контекстах, лежащих вне дискурса, где фраза изначально зародилась. Так, например, страны Иран, Ирак и Северная Корея с легкой руки Дж. Буша попали в ось зла «Axis of Evil»» ${ }^{2}$. Впоследствии фраза часто использовалась в контексте оправдания «войны против терроризма» - военных операций США в Афганистане и Ираке. Подавляющее большинство ПФ-употреблений в англоязычном цифровом медиадискурсе представляют собой прямые цитации, связанные с международной обстановкой. Однако, согласно корпусным данным, «Axis of Evil» может употребляться и за пределами политического дискурса. Так, в канадском английском с осью зла ассоциируют три любых отрицательных элемента, например «зимняя ось зла» состоит из снега, слякоти и льда (пример 1).

(1) We've met on a sunny morning and set off in search of winter's axis of evil: snow, slush and ice (https://www.thestar.com 09.01.2010 CA).

Очевидно, здесь (пример 1) мы имеем дело с достаточно высокой степенью модификации ПФ. Встает вопрос: «зимняя ось зла» и «ось зла» - это одно и то же? А если это «ось добра» (пример 2), это вариация Axis of evil? Безусловно, с увеличением степени модификации ПФ меняется его функциональная нагрузка, а значит снижается и его узнаваемость, слабеет его коммуникативная интертекстуальная востребовательность. Однако до тех пор, пока остаются «следы» связи ПФ Axis of evil с контекстным употреблением Axis of Good (ось добра), например в виде фрейма, последнее целесообразно считать вариацией ПФ Axis of evil.

(2) Dieudonné came on stage roughly disguised as " a convert to Zionist extremism" advising others to get ahead by "joining the American-Israeli Axis of Good" (https://www.counterpunch.org 01.01.2014 US).

Определенным фильтром для ограничения исследовательского корпуса ПФ стало использование ПФ

${ }^{2}$ Фраза, использованная Президентом США Дж. Бушем в обращении к Конгрессу в 2002 г., пять месяцев спустя после теракта 11 сентября 2001 г. Осью зла он назвал государства, которым приписывали спонсирование террористов и создание оружия массового поражения: Иран, Ирак и Северную Корею. 
в качестве слогана, например на выборах. К примеру, не подвергается сомнению прецедентность слогана Д. Трампа “Make America Great Again” (9533 употребления в корпусе NOW), который известен далеко за пределами медийного дискурса США и часто становится объектом языковой игры в формате “Make $X$ Great Again" (2433 употребления в корпусе NOW). Аналогично функционируют и британские политические слоганы. Например, «Get Brexit Done» ${ }^{3}$ (2296 употреблений в корпусе NOW в подавляющем большинстве в медиадискурсе Великобритании и Ирландии). Однако, чтобы не нарушать строгости количественного анализа, было решено оставить подобные слоганы за рамками настоящего исследования как созданные не стихийно, а намеренно, и изначально нацеленные на широкое распространение (сувенирная продукция, реклама). Очевидно, становление прецедентности таких ПФ-слоганов в медиадискурсе осознанно культивируется.

Знаменательные исторические фразы У. Черчилля: «We shall fight on the beaches» или «We shall never surrender», в принципе удовлетворяющие первому критерию отбора материала, также не вошли в список ПФ для анализа. Показательно, что данные ПФ не отличаются высокой частотностью употребления. Безусловно, значимость ПФ не связана с его «возрастом» напрямую, но тем не менее нередко наблюдается снижение значимости, а значит и прецедентности таких ПФ при смене поколений, а с момента речей У. Черчилля сменилось не одно поколение. Заметим при этом, что подавляющее большинство корпусных ПФ-употреблений относится к цитированию прецедентного текста речи политика целиком или подборкам цитат из его речей: например, статья с названием «12 Winston Churchill Quotes to Live By» ${ }^{4}$.

В проведенный количественный анализ не включена область контекстов, которые условно можно назвать «про прецедентное высказывание»: списки и подборки цитат, объяснение значений прецедентных высказываний, текст, посвященный сериалу-источнику или актеру, которому высказывание принадлежит (пример 3). Таких контекстов употребления «про ПФ» оказалось $13 \%$.

(3) She followed that with The Weakest Link, which spawned one of the nation's favourite catchphrases: "You are the Weakest Link! Goodbye!" (https://www.

${ }^{3}$ Слоган Консервативной партии Великобритании во время кампании 2017 г.

${ }^{4}$ https://www.townandcountrymag.com/ 06.11.2017 US.

5 Фраза ведущего передачи «Слабое звено», изначально появившейся на британском телевидении, но впоследствии получившей распространение и в других странах. В русской версии передачи эта фраза звучит как «Вы - самое слабое звено! Прощайте!». Часто используется как синоним слову неудачник или как указание на то, что человек с чем-то не справился. sundaypost.com 29.09.2017 GB). Вы - слабое звено, прощайте!

Более того, одна специфическая особенность медийного телевизионного дискурса также не позволила включить некоторые ПФ в исследование. Источником фраз, которые потом выступают в функции ПФ, часто являются юмористические шоу или передачи, где комический эффект достигается за счет фонетической трансформации фразы (a complete dahnce diSAH-ster ${ }^{6}$ и Tank you veddy much ${ }^{7}$ ), в которых особенности произношения переданы через нестандартную орфографию. В корпусе NOW такие примеры представлены единично, а так как именно произношение зачастую делает фразу прецедентной, узнаваемой, то фразы, написанные без фонетической стилизации, не могут считаться отсылками к прецедентной ситуации. Модификации такого типа ПФ целесообразно изучать на данных устного языкового корпуса.

В результате жесткого отбора ПФ исследовательский корпус сократился до 10 фраз из политического дискурса (6712 ПФ-употреблений) и 10 фраз из телевизионного дискурса (1999 ПФ-употреблений). Неравномерно разделились и варианты английского языка, которые стали средой порождения и функционирования прецедентных высказываний. На 14 ПФ, рожденных в американском варианте английского, приходится 4 ПФ британского, 1 австралийского и 1 ирландского вариантов английского языка (таблица). Любопытно, что эти данные соотносятся с результатами недавнего исследования о мировых медиапотоках, которое показало, что на долю США приходится более 3/4 телепередач и фильмов, проданных на мировом рынке за последние десятилетия $[14$, c. 145$]$.

\section{Результаты исследования и их обсуждение}

Как видим (таблица), количество ПФ с высокой долей прямого цитирования (столбец 3) невелико, лидерами являются Axis of evil (96,9\%) и The tribe has spoken $^{8}$ (96,7 \%). Однако и для таких «высокоустойчивых» ПФ наблюдаются модификации, например, «Ось Добра» (пример 2), или «решение племени телеканала Спинофф» (пример 4):

(4) The Spinoff tribe has spoken: it's going to be good (https://thespinoff.co.nz 11.01.2017 NZ).

\footnotetext{
${ }^{6}$ Коронная фраза одного из судей британского танцевального шоу "Strictly Come Dancing".

${ }^{7}$ Коронная фраза комика Энди Кауфмана в его выступлениях в образе персонажа «Иностранец».

${ }^{8}$ Фраза из британского реалити-шоу “Survivor", в котором участники должны были выживать на острове. Группа участников называлась «племя», на еженедельном собрании которого определялось, кто выбывает из шоу. Фраза The tribe has spoken произносилась перед объявлением такого или подобного важного решения. Ср. российский аналог-реалити-шоу «Последний герой».
} 
Соотношение прямых цฺитацฺий и квазицฺитацฺий

\begin{tabular}{|l|c|c|}
\hline \multicolumn{1}{|c|}{$\begin{array}{c}\text { Прецедентное высказывание } \\
\text { (в скобках указана страна происхождения })^{9}\end{array}$} & $\begin{array}{c}\text { Общее количество ПФ- } \\
\text { употреблений }\end{array}$ & $\begin{array}{c}\text { Количество прямых цитаций } \\
(\%)\end{array}$ \\
\hline Drain the swamp (US) & 2642 & $1137(96,9 \%)$ \\
\hline Axis of evil (US) & 1173 & $733(82,4 \%)$ \\
\hline Coalition of the willing (US) & 890 & $552(74,4 \%)$ \\
\hline Think of the children / What about the children? (US) & 742 & $381(63,9 \%)$ \\
\hline A week is a long time in politics (GB) & 596 & $203(94 \%)$ \\
\hline Ladder of opportunity (AU) & 216 & $135(94,4 \%)$ \\
\hline Fuzzy math (US) & 142 & $55(44,7 \%)$ \\
\hline Vote early and vote often (US) & 123 & $96(87,3 \%)$ \\
\hline An Irish solution to an Irish problem (IE) & 110 & $75(96,1 \%)$ \\
\hline Misunderestimate (US) & 78 & $459(82,9 \%)$ \\
\hline May the Force be with you (US) & 554 & $152(50,5 \%)$ \\
\hline Beam me up, Scotty (US) & 301 & $181(68 \%)$ \\
\hline Houston, we have a problem (US) & 266 & $105(44,3 \%)$ \\
\hline Hasta la vista, baby (US) & 237 & $165(82,5 \%)$ \\
\hline Computer says no (GB) & 200 & $122(78,2 \%)$ \\
\hline Why so serious? (US) & 156 & $68(53,5 \%)$ \\
\hline Toto, I've a feeling we are not in Kansas anymore (US) & 127 & $16(23,5 \%)$ \\
\hline I love the smell of napalm in the morning (US) & 68 & $45(96,7 \%)$ \\
\hline The tribe has spoken (GB) & 47 & $38(88,4 \%)$ \\
\hline You are the weakest link (GB) & 43 & \\
\hline
\end{tabular}

Предельно низкие (3 \%) показатели модификационной способности ПФ и ограничения на изменения ПФ (в виде атрибутивного расширения имени, как в примере 5 - осушить налоговое болото или в примеpe 6 - осушить морально-нравственное болото), можно объяснить несколькими причинами. Во-первых, размер ПФ явно влияет на его модификационную способность. Чем длиннее фраза, тем нагляднее ее склонность к вариативности. Вторым фактором выступают ограничения на сочетаемость компонентов ПФ: например, в выражении Drain the swamp собственная лексическая сочетаемость как глагола, так и существительного не предусматривает широкой вариативности или антонимии "

(5) Two questions Trump must answer if he wants to drain the tax swamp (https://www.theguardian.com/ 21.04.2017 GB).

(6) The first and most important "what" of a conceptual future political leadership in Pakistan is the

\footnotetext{
9 Данные о странах указаны в том формате, в котором они представлены в корпусе NOW. Расшифруем используемые в данной статье аббревиатуры: $\mathrm{AU}$ - Австралия, CA - Канада, GB - Великобритания, GH - Гана, IE - Ирландия, IN - Индия, $\mathrm{KE}$ - Кения, NZ - Новая Зеландия, PH - Филиппины, SG Сингапур, US - США.
}

impeccable requirement of a personal reputation for incorruptibility to drain the ethical-moral swamp of the Zar-Naw Brothers' years of mass corruption and mismanagement of the nation's resources (https://tribune. com.pk 24.11.2017 PK).

Наблюдения за функционированием ПФ в цифровом медиадискурсе и изучение опыта других исследователей языковой вариативности (см., например, Н. Джанич [15, pp. 178-179]) позволяют рассмотреть возможности и формы проявления квазицитирования, обобщив их в виде основных принципов модификации ПФ.

1. Добавление к прецедентному тексту нового элемента, который может стоять как в начале (пример 7), так и в конце фразы, измеряться полноправным предложением и существенно корректировать авторское намерение: Мы больше не в Канзасе, да мы и не были никогда в Канзасе (пример 8).

(7) Better call Toto, we're not in Kansas anymore (https://www.huffpost.com 25.09.2014 US).

(8) To paraphrase Dorothy from The Wizard of $\mathrm{Oz}$, if correct, this extrapolation implies that we are not in Kansas anymore, and, in fact, we never were in Kansas (https://news.stanford.edu 23.02.2012 US).

В ряде случаев вариации на тему «мы больше не в Канзасе» могут выйти за рамки предложения, раз- 
вивая прецедентную ситуацию дальше ( больше не там, где был когда то, пример 9):

(9) We are not in Kansas anymore. More importantly, Kansas is not even where it once was (https://fyiliving. com/ 13.09.2010 US).

2. Замена одного или нескольких элементов ПФ другими лексическими единицами. Чаще всего это контекстно обусловленные элементы, которые заменяют обращения Toto $\rightarrow$ Tom или топонимы Kansas $\rightarrow$ Kansas City Fed (пример 10).

(10) But, as Dorothy might have said, “ Tom, Tom, I've a feeling we're not at the Kansas City Fed now and you're losing the fight (https://blogs.wsj.com 26.10.2010 US).

Заметим, что у всех четырех фраз с обращением, например, Beam me up, Scotty (таблица), доля прямых цитаций едва превышает половину ПФ-употреблений, что указывает на склонность ПФ к изменчивости и, как следствие, к вариативности.

Помимо чисто контекстно обусловленных элементов, части прецедентных высказываний могут заменяться антонимами (пример 11), синонимами children $\rightarrow$ kids (пример 12) или просто членами одной парадигмы, например глаголов действия vote $\rightarrow$ win в ПФ Vote early and vote often (пример 13, 14).

(11) Such an alliance could rightly be dubbed an 'axis of good, 'a salutary and beneficial counterbalance to one or more axes of evil that today imperil global peace and prosperity (https://www.livemint.com 05.07.2017 IN).

(12) When you see our local pollies on the campaign trail, ask them: What about the kids? ${ }^{10}$ (https://www. frasercoastchronicle.com.au 31.10.2017 AU).

(13) Tight-knit or not, a top three placing will be in the cards for the Slovakians if they win. Win early and win often ${ }^{11}$ (https://www.nhl.com 05.02.10 CA).

Анализ показал, что квазицитированию скорее подвержены фразы, прецедентность которых достаточно устойчива ${ }^{12}$. И это легко объяснимо. Замена элементов менее известной фразы с неустойчивой прецедентостью может привести к тому, что нарушится связь квазицитации с ситуацией-источником, квазицитата утратит свою прецедентность если не для всех, то для многих пользователей. Возьмем для

${ }^{10}$ Фраза часто используется в качестве риторического приема, заменяя логические аргументы эмоциональным воздействием. Призыв подумать о детях в контексте некой, часто преувеличенной угрозы, отвлекает внимание слушающих от аргументации говорящего, «отключает» разум аудитории.

${ }^{11}$ Вариация фразы Vote early and vote often, которая берет свое начало в XIX в. в политическом дискурсе США, может трактоваться как призыв к саботажу путем голосования более чем единожды в одних выборах, с раннего утра посетив несколько участков. Может использоваться без негативной коннотации, чтобы поощрить какое-то поведение.

12 Устойчивость прецедентности фразы измеряется количеством ее употреблений в функции ПФ в корпусе. примера фразу британского политика Г. Вильсона (1916-1995) a week is a long time in politics (596 ПФупотреблений), суть которой заключается в том, что за неделю в политической обстановке многое может поменяться. Достаточная степень устойчивости прецедентности данной фразы обусловливает относительно высокую долю квазицитаций с заменой politics на другие сферы деятельности в основном из спорта: football (пример 14), rugby, sport, racing.

(14) A week is a long time in football, or so the cliche goes (http://www.foxsportsasia.com 02.11.2017 PH).

3. Усечение ПФ, опущение его части, чаще всего обращения, как в примере 15 . Подобные модификации делают фразу более универсальной и лапидарной, что, однако, может снизить ее узнаваемость для коммуникантов.

(15) The look is inspired by an "intergalactic traveler", according to the media materials. I say beam me $\boldsymbol{u p}^{13}$ (https://latimesblogs.latimes.com/ 27.08.2010 US).

Помимо обращений, подвергаться опущению могут и другие части прецедентного феномена. Так, в примере 16 ПФ «An Irish solution to an Irish problem» усечен вдвое, что, тем не менее, не снижает его узнаваемости.

(16) Across the country, different garda superintendents applied separate interpretations of law enforcement - an Irish solution (https://www. irishexaminer. com / 19.08.2010 IE).

Для некоторых достаточно длинных фраз можно выявить факультативные часто усекаемые элементы. Так, в прецедентном высказывании Toto, (I've a feeling) we're not in Kansas anymore факультативной является часть, заключенная в скобки. Остается открытым вопрос, до какой степени может усекаться прецедентное высказывание, не теряя своей узнаваемости?

4. Смешение элементов двух и более ПФ. Пример 17 демонстрирует слияние ПФ из одного источника (Волшебник страны Оз Л. Баума) и ПФ из другого (Алиса в Стране чудес Л. Кэрролла), где происходит замена топонимов Kansas $\rightarrow$ Wonderland и обращений Toto $\rightarrow$ Alice. При этом ПФ “we're not in Kansas anymore” продолжает выполнять свою коммуникативную функцию.

(17) We're not in Wonderland anymore, Alice (https://prime.economictimes. indiatimes.com/ 14.12.2019 IN).

${ }^{13}$ Полная форма фразы - Beam me up, Scotty принадлежит персонажу Капитану Кирку из американского научно-фантастического сериала «Звездный путь». Под beam up подразумевается телепортация с помощью луча на космический корабль, к которой Кирк прибегал в тех случаях, когда у него начинались проблемы. Может использоваться для описания телепортации в целом или чтобы выразить нежелание более где-либо находиться. 
5. Вариации в стяжении. Использование полной формы глагола и отрицательной частицы (или местоимения и глагола) вместо сокращенной формы (пример 18) или наоборот, использование стяжения в тех фразах, где изначально его не было (пример 19).

(18) What have we always said? We are not in Kansas anymore, Toto. We are firmly in 2018, a pre-election year (https://www.moneycontrol.com/ 29.06.2018 IN).

(19) One reporter wanted to know why he had screamed 'you're the weakest link' to his partner (https:// sg.news.yahoo.com/ 05.07.2019 SG).

Стоит отметить, что у прецедентного феномена you are the weakest link, goodbye примеров употребления с сокращенной формой уои're достаточно мало, что можно объяснить эмфатическим характером полной формы глагола.

6. Смешанные модификации ПФ, например усечение ПФ «Vote early and vote often» до Vote early (,) and often (таких квазицитаций в выборке 31) и замена vote $\rightarrow$ save, что совершенно меняет смысл ПФ. Как видим, в медийном дискурсе Филиппин детей приучают «копить деньги с детства и часто» (примep 20).

(20) Learning to save early, and often, is an important lesson to teach your kids (https://www. wisebread.com/ 13.05.2018 PH).

В выборке также есть модифицированный ПФ, подвергшийся нескольким типам изменений: добавлению, усечению, замене и вариации в стяжении (пример 21).

(21) No, Toto, we are not in Selma anymore (https:// thefederalist.com/ 28.07.2016 US).

В квазицитацию добавлено "No", отсечено “I've a feeling”, используется полная форма глагола, и имеет место замена Kansas $\rightarrow$ Selma. Следует отметить, что вариации в стяжении - достаточно распространенный тип модификаций. Он встречается практически во всех прецедентных высказываниях нашей выборки, допускающих подобную форму квазицитирования, и часто комбинируется с другими видами модификаций.

7. ПФ в атрибутивной позиции при существительном (примеры 22-24).

(22) Polling for the Royal Society of Arts (RSA) found widespread concern that AI will create a "Computer Says No" culture $^{14}$, in which crucial decisions are made automatically without consideration of individual circumstances (http://www.heraldscotland.com/ 30.05.2018 GB).

${ }^{14}$ Фраза персонажа британского сатирического телесериала "Little Britain". Банковский служащий Кэрол Бир отвечает такой фразой на любой запрос клиента, предварительно набрав его на клавиатуре. Используется, чтобы подчеркнуть трудности работы с некоторыми организациями, где много операций происходит через интернет-обращение.
(23) Let's give Treasury officials the benefit of the doubt and call this the "fuzzy math"15 question (https:// www.businessdailyafrica.com/ 29.07.2018 KE).

(24) Teleportation: I know this sounds like beam-meup-Scottie stuff, but it's not (https://www.forbes.com/ 18.08.2019 US).

В большинстве контекстов ПФ в атрибутивной позиции маркируется кавычками (примеры 22-23), в ряде случаев каждое слово фразы выделяется заглавной буквой (пример 22), иногда элементы фразы соединяются дефисами (пример 24) - типичный и регулярный, по мнению Л. Бауэра, способ маркирования фразовых композитов в английском языке [16, р. 56]. Хотя степень семантической прозрачности ПФ в атрибутивной позиции достаточно высокая, более половины примеров выборки снабжены дополнительными разъяснениями смысла приписанной объекту характеристики, как в примере 22, где речь идет о культуре искусственного интеллекта, в которой компьютер автоматически отказывает (говорит «нет») человеку.

Вероятно, такой способ квазицитирования ПФ целесообразно считать разновидностью его преобразования. Спецификой данного ПФ-употребления является отсутствие лексической вариативности фразового композита, что, однако, не распространяется на вариации в стяжении (пример 25).

(25) Reminded me of Sharknado Part 2 and Wizard of $\mathrm{Oz}$ "Toto, I have a feeling we are not in Kansas anymore" vibes (http://koalasplayground.com/ 13.12.2019 SG).

Отдельно следует рассмотреть содержательное варьирование ПФ. Единичные примеры ПФ-употребления наглядно демонстрируют, как ПФ на определенном этапе своего коммуникативного обращения меняет значение. При этом семантические изменения не обязательно затрагивают все англоязычное пространство, а проявляются выборочно, в некоторых его частях. Рассмотрим семантический сдвиг ПФ на примере прецедентного высказывания, изначально появившегося в ирландском политическом дискурсе: An Irish solution to an Irish problem. В середине XX в. данный ПФ ассоциировался исключительно с положительной коннотацией, а именно, что проблемами Ирландии должны заниматься ирландцы (пример 26).

${ }^{15}$ Фраза американского политического дискурса, чтобы обозначить ситуацию, при которой заявленные правительством суммы (например, трат), при детальном рассмотрении не сходятся. Одним из первых ее использовал Джордж Буш для того, чтобы поставить под сомнение суммы, озвученные его противником по дебатам. Используется в контексте подтасовки количественных данных. Ср. с имеющим хождение в русскоязычном политическом дискурсе выражением «146\%». 
(26) May I express the hope that we will try more consistently to bring about an Irish solution to our own problems without seeking merely to apply here something they have done successfully or otherwise elsewhere? (Voluntary Health Insurance Bill, 1956).

Парадоксально, но в корпусе NOW, который охватывает медиадискурсивное творчество в двадцати региональных вариантах английского языка с 2010 г. по настоящее время, практически отсутствуют ПФупотребления в исходном значении с положительной коннотацией. Вероятно, действия ирландского правительства не раз получали ироническую оценку в англоязычном мире, в частности в США, что закрепило отрицательную коннотацию за ПФ «решение ирландской проблемы по-ирландски» (пример 27).

(27) Kennedy says it will probably take a major tragedy before the situation is properly addressed. " $\underline{A n}$ Irish solution to an Irish problem. Manage only by crisis. Never anticipate" (https://www.irishtimes.com/ 30.06.2018 US).

В данном случае можно говорить об энантиосемии или внутрисложной (внутрифразовой) антонимии, т. е. появлении у лексической единицы противоположного значения, которое может как вытеснить первоначальное, так и сосуществовать с ним. В данном случае источником энантиосемии стал антифразис - стилистическая фигура отрицания, когда слово (словосочетание, предложение) стало употребляться в основном в противоположном смысле [17, с. 145], часто иронически.

Любопытно при этом, что мы наблюдаем сосуществование двух вариаций ПФ «An Irish solution to an Irish problem» и «a(n) X solution to a (n) X problem». В первом случае коннотация отрицательная, во втором - положительная (пример 28). В остальных вариантах английского языка ПФ $a(n) X$ solution to $a(n) X$ problem употребляется в первоначальном значении.

(28) "We have found at last an African Solution to an African problem" he proudly declared on the floor of Parliament on Wednesday. He was excited that the subregional body ECOWAS did not wait for help from elsewhere but found it expedient to act swiftly (www. ghanaweb.com 15.02.2017 GH).

\section{Заключение}

Цифровая среда и параметры коммуникативного обращения ПФ способствуют его только формальному, только содержательному, формально-содержательному или функциональному варьированию. ПФ, «дожившие» до этапа модификации, демонстрируют разную степень изменчивости и вариативности. Соотношение прямого цитирования и квазицитирования зависит от длины ПФ и сочетаемостных особенностей его элементов. Вариативность ПФ проявляется в «перемене мест слагаемых», в смешивании с другими прецедентными феноменами, а также в сокращении или увеличении количества элементов ПФ. Увеличение достигается за счет добавления новых элементов, на $90 \%$ атрибутивов (Ladder of urban opportunity). Вариативность ПФ также связана с контекстно обусловленной заменой его элементов (apply early and apply often).

«Высшим пилотажем» интертекстуальности с максимально высокой степенью устойчивости, по всей видимости, следует считать употребление ПФ в атрибутивной позиции при существительном, что подчеркивает его целостность, а также однозначность и прозрачность интерпретации (the "fuzzy math" question). Атрибутивная группа может пунктуационно маркироваться разными способами: с помощью кавычек, капитализации каждого слова в фразе или использования дефисов между ее членами. Редким, но тем не менее ярким способом модификации ПФ по данным корпуса NOW являются различия в толковании смысла ПФ, характерные для разных частей англоязычного пространства.

\section{ЛИТЕРАТУРА}

1. Донина О. В. Применение методов data mining для решения лингвистических задач // Вестник Воронеж. гос. ун-та. Сер.: Системный анализ и информационные технологии. 2017. № 1. С. 154-160.

2. Гришаева Л. И. Интертекстуальность как фактор риска в переводческой деятельности // Язык, коммуникация и социальная среда. Воронеж, 2012. Вып. 10. C. $46-68$.

3. Гришаева Л. И., Цурикова Л. В. Теория межкультурной коммуникации : Проблемы, подходы, анализ : монография. Воронеж : Издательский дом ВГУ, 2018. $505 \mathrm{c}$.

4. Budaev E., Chudinov A. P. Transformations of precedent text : Metaphors we live by in academic discourse // Вопросы когнитивной лингвистики. 2017. № 1 (50). C. 60-67.

5. Гришаева Л. И. Арминий, Барбаросса, ведьмы с Брокена и другие : Нем. яз. и культура через призму нем. прецедент. текстов : учеб. пособие. Воронеж : Воронеж. гос. ун-т, 1998. $147 \mathrm{c}$.

6. Сльшикин Г. Г. От текста к символу : лингвокультурные компоненты прецедентного текста в сознании и дискурсе. М., 2000. 125 с.

7. Bogoyavlenskaya Y. V., Nakhimova E. A., Chudinov A. P. Precedent utterances in the national historical memory: A corpus study // Voprosy Kognitivnoy Lingvistiki. 2016. № 2 (47). Pp. 39-48.

8. Кремнёва А. В. Интертекстуальность как одна из форм межтекстового взаимодействия в семиотическом пространстве культуры. Барнаул : АлтГТУ им. И. И. Ползунова, 2017. 378 с. 
9. Костомаров В. Г., Бурвикова Н. Д. Как тексты становятся прецедентными // Русский язык за рубежом. М., 1994. № 1. С. 73-76.

10. Феномен прецедентности и преемственности культрур / под общ. ред. Л. И. Гришаевой, М. К. Поповой, В. Т. Титова. Воронеж : Воронежский государственный университет, 2004. 312 с.

11. Davies M. Corpus of News on the Web (NOW): $6+$ billion words from 20 countries, updated every day. Provo, 2013. URL: https://www.english-corpora.org/now/

12. Boriskina $O$. O. A corpus-based study of noun cryptotypes in English // Компьютерная лингвистика и интеллектуальные технологии : материалы ежегод. Междунар. конф. М., 2011. С. 135-145.

13. Караулов Ю. Н. Русский язык и языковая личность. М. : Наука, 1987. 216 с.

14. Грицан А. В. Роль США в мировых медиапотоках и их влияние на аудиовизуальный рынок России // Вестник Нижегор. ун-та им. Н. И. Лобачевского. Сер.: Социальные науки. 2016. № 3 (43). С. 139-148.

15. Džanić N. D. Conceptual Integration Theory the key for unlocking the internal cognitive choreography of idiom modification // Jezikoslovlje. 2007. T. 8, № 2. Pp. 169-191.

16. Bauer L., Lieber R., Plag I. The Oxford reference guide to English morphology. Oxford University Press, 2015. $718 \mathrm{p}$.

17. Дронов П. С. Общая лексикология. М. : Языки славянской культуры, 2015. 224 с.

\section{REFERENCES}

1. Donina O. V. Primenenie metodov data mining dlya resheniya lingvisticheskikh zadach [Using data mining methods for linguistic purposes] Vestnik Voronezhskogo gosudarstvennogo universiteta. Seriya: Sistemnyj analiz $i$ informatsionnye tekhnologii. 2017. No. 1. Pp. 154-160.

2. Grishaeva L. I. Intertekstual `nost` kakfaktor riska $v$ perevodcheskoj deyatel nosti [Intertextuality as a risk factor in translation] Yazy $k$, kommunikaciya i social naya sreda. Issue 10. Voronezh, 2012. Pp. 46-68.

3. Grishaeva L. I., Tsurikova L. V. Teoriya mezhkul 'turnoj kommunikacii : Problemy', podxody', analiz : monografiya [Intercultural communication theory : Problems, Approaches, Analysis] VSU, Voronezh : Izdatel`skij dom VGU, 2018. 505 p.

4. Budaev E., Chudinov A. P. Transformations of precedent text: Metaphors we live by in academic discourse. Voprosy 'kognitivnoj lingvistiki. 2017. No. 1 (50). Pp. 60-67.

5. Grishaeva L. I. Arminij, Barbarossa, ved'my s Brokena $i$ drugie : Nem. yaz. i kul'tura cherez prizmu nem.

Воронежский государственный университет

Шимко В. Г., магистрант кафедры теоретической и прикладной лингвистики

E-mail:vshimko.vrn@gmail.com pretsedent. tekstov [Arminius, Barbarossa and Brocken witches: the German language and culture through the lens of precedent texts]. Voronezh : Voronezh gos. un-t, 1998. $147 \mathrm{p}$.

6. Sly`shkin G. G. Ot teksta k simvolu: lingvokul 'turny`e komponenty 'precedentnogo teksta $v$ soznanii $i$ diskurse [From text to meaning : linguocultural components of precedent text in perception and in discourse] Moscow, 2000. $125 \mathrm{p}$.

7. Bogoyavlenskaya Y. V., Nakhimova E. A., Chudinov A. P. Precedent utterances in the national historical memory: A corpus study. Voprosy Kognitivnoy Lingvistiki. 2016. No. 2 (47). Pp. 39-48.

8. Kremnyova A. V. Intertekstual 'nost 'kak odna iz form mezhtekstovogo vzaimodejstviya $v$ semioticheskom prostranstve kul'tury' [Intertextuality as one of the forms on intertextual interaction within the semiotic domain of culture] Barnaul : AltGTU im. I. I. Polzunova, 2017. 378 p.

9. Kostomarov V. G. Kak teksty' stanovyatsya precedentny 'mi [How texts become precedent] Russkij yazy`k za rubezhom Moscow, 1994. No. 1. Pp. 73-76.

10. Fenomen precedentnosti i preemstvennosti kul trur [The phenomenon of precedence and the succession of cultures]. Voronezh: Voronezhskij gosudarstvenny ’j universitet, 2004. 312 p.

11. Davies M. Corpus of News on the Web (NOW): $6+$ billion words from 20 countries, updated every day. Provo, 2013. Available at: https://www.english-corpora.org/now/

12. Boriskina O. O. A corpus-based study of noun cryptotypes in English. Komp yuternaya lingvistika i intellektual 'ny'e texnologii. Materialy ezhegodnoj Mezhdunarodnoj konferencii. M., 2011. Pp. 135-145.

13. Karaulov Yu. N. Russkij yazy`k $i$ yazy kovaya lichnost' [The Russian language and linguistic persona] Moscow: Nauka, 1987. 216 p.

14. Griczan A. V. Rol'SShA v mirovy'x mediapotokax $i$ ix vliyanie na audiovizual ny ’ $\mathrm{ry}$ 'nok Rossii [The role of the USA in the global media flows and their influence on Russian audiovisual market] Vestnik Nizhegorodskogo universiteta im. N. I. Lobachevskogo. Seriya: Social’ny`e nauki. 2016. No. 3 (43). Pp. 139-148.

15. Džanić N. D. Conceptual Integration Theory - the key for unlocking the internal cognitive choreography of idiom modification. Jezikoslovlje. 2007. Vol. 8. No. 2. Pp. 169-191.

16. Bauer L., Lieber R., Plag I. The Oxford reference guide to English morphology. Oxford University Press, 2015. $718 \mathrm{p}$.

17. Dronov P. S. Obshhaya leksikologiya [General lexicology] Moscow: Yazy 'ki slavyanskoj kul 'tury’, 2015. 224 p.

Voronezh State University

Shimko V. G., Student of the Theoretical and Applied Linguistics Department

E-mail:vshimko.vrn@gmail.com 
Вариации прецедентных феноменов в медиадискурсе...

Борискина О. О., доктор филологических наук, профессор кафедры теоретической и прикладной лингвистики

E-mail: boriskinatipl@mail.ru

Поступила в редакиию 13 марта 2020 г.

Принята к публикаџии 15 июня 2020 г.

\section{Для цичтирования:}

Шимко В. Г., Борискина О. О. Вариации прецедентных феноменов в медиадискурсе, или еще одна попытка «поверить алгеброй гармонию» // Вестник Воронежского государственного университета. Серия: Лингвистика и межкультурная коммуникация. 2020. № 3 . C. 15-24. DOI: https://doi.org/10.17308/lic.2020.3/2926
Boriskina O. O., Doctor of Philology, Professor of the Theoretical and Applied Linguistics Department

E-mail: boriskinatipl@mail.ru

Received: 13 March 2020

Accepted: 15 June 2020

\section{For citation:}

Shimko V. G., Boriskina O. O. The variation of catchphrases in digital media. Proceedings of Voronezh State University. Series: Linguistics and Intercultural Communication. 2020. No.3. Pp. 15-24. DOI: https://doi.org/10.17308/ lic. $2020.3 / 2926$ 